\section{American Men of Science}

A Biographical Directory. Edited by Jaques Cattell. Seventh edition. Pp. vii +2033. (Lancaster, Pa. : Science Press, 1944.) 14 dollars.

$\mathrm{T}$ HERE is no published record in Great Britain from which one can obtain the scientific record of a particular individual, apart from those included in "Who's Who". Attempts have been made to meet the need, but they have not persisted. North America is more fortunate. Since 1906 it has had "American Men of Science", now in its seventh edition. It is a bulky volume, in spite of the large page used, but the type is admirably clear, as should be the case in any reference book.

For those not familiar with this work, it can be described as an alphabetical list of scientific men (and women) of the United States and Canada. Under each name the following data are given : address; date and place of birth; academic distinctions with dates; posts occupied, again with dates; member. ship of scientific societies, with offices held; and chief scientific interests. By the ingenious use of abbreviations and italics, a surprising amount of information is provided. It is estimated that the present volume contains 34,000 names, as against 4,000 in the first edition. 250 names are marked with an asterisk as those of leaders in their particular subjects during the past five years; they are selected by popular vote.

No doubt such a compilation is expensive to produce and to keep under continuous revision, but its usefulness makes it well worth while. Is it too much to hope that the money will be fortheoming for a similar reference book of British men of science? Much of the necessary material is already in existence on the cards of the Central Register held by the Ministry of Labour and National Service.

\section{Elementary Statistics}

By Prof. Hyman Levy and E. E. Preidel. (Nelson's Aeroscience Manuals.) Pp. vii + 184. (London andEdinburgh : Thomas Nelson and Sons, Ltd., 1944.) 5s. net.

THIS volume, in the series of Nelson's Aeroscience Manuals, covers the elementary ideas of statistical theory, including distributions, means, measures of dispersion, correlation, elements of probability, least squares and the normal distribution. The mathematics required are not very advanced and are carefully explained; and there are numerous examples and exercises. The book should be useful in giving a general idea of the subject to those who do not wish to specialize in it.

Statistical nomenclature is always something of a problem, but there are two expressions used in this book which the authors might reconsider. They refer to the arbitrary origin chosen to simplify the calculation of a mean as a "fictitious average", whereas most writers use the more descriptive phrase "working mean"; and later on extend their usage to a "fictitious standard deviation" for the root-meansquare. Secondly, the authors give the result that the probability of $r$ events in $n$ trials with probability $p$ is $\left(\begin{array}{l}n \\ r\end{array}\right) p^{r}(1-p)^{n-r}$ and call it Bernoulli's theorem. The result was certainly given by James Bernoulli (though Pascal probably knew it); but what is now generally known as his theorem in probability is the much more advanced result at the end of the "Ars Conjectandi", to the effect that the proportion of successes in repeated trials approaches $p$ with as great a probability as is desired.
Introduction to Differential Equations

By S. L. Green. Pp. iv + 140. (London: University Tutorial Press, Ltd., 1945.) 7s. 6d.

$\mathbf{T}$ is quite refreshing to see a new book on differontial equations, and this introduction to the subject has been planned with skill and developed with a clear appreciation of the difficulties which usually confront the student. There are eight interesting chapters covering ordinary and first-order equations, including Bernoulli's equation, with applications to plane curves. Then follows a thoroughly sound treatment of partial equations and operational methods, with illustrations from surfaces and curves in space. Next come Lagrange's linear equation and total equations in three variables. Finally, there is a well-written chapter on solutions in series, embracing the method of Frobenius, Bessel's equation of order zero, and Laplace's equation.

The book is intended for students reading for university degrees in the faculties of arts, science and engineering. The course is one of pure rigorous mathematics with very few practical applications of the kind required by science and engineering students, although in the very numerous exercises set for the student's practice, several are drawn from physical problems. Nevertheless, the author has produced a thoroughly good book which gives a clear insight into some of the fundamental principles of so vast a subject. Not only is the volume of value to the student who is under the expert guidance of a teacher, but also the clarity of the style renders the text very readable and understandable to an intelligent private student. As the specialists in this subject are now unfortunately few, the book should be useful also to teachers for, after all, differential equations are fundamental to all applied science and engineering.

The book can be confidently recommended to all to whom the study of the subject is indispensable.

The Theory of Measure in Arithmetical Semi-Groups By Aurel Wintner. Pp. v+56. (Baltimore, Md. : The Author, Johns Hopkins University, 1944.) 2 dollars.

7 HIS monograph, the title of which is somewhat abstruse, deals in fact with certain aspects of prime-number theory. Though self-contained in presentation, it is a continuation of the author's "Eratosthenian Averages" (Baltimore, 1943). A knowledge of analytical prime-number theory and of Tauberian theorems is assumed, and even readers possessing this knowledge will probably not find the book easy reading. The greater part of it is concerned with the properties of the set of all integers that are divisible only by the primes of a given sequence, and in particular the various senses in which the set may have a 'density'.

The attitude throughout is typical of one tendency in present-day mathematics: there is a detailed analysis of the logical relation between every proposition and (almost) every other, and of the 'depth' of each proposition. Much of this is interesting and instructive, but I cannot help thinking that the book would have been more readable if the author had been less thorough.

There is a mistake (not important for the sequel) on p. 32 : if $L(x)$ is a monotonic function which tends to infinity with $x$, and if $L(x)=O\left(x^{8}\right)$ for every positive $\varepsilon$, it does not follow that $L(x) \sim L(\theta x)$ for every fixed positive $\theta$. The author has been misled by a statement of Pringsheim. H. DAvenPort. 